\title{
Efficacy of natural compounds from Tinospora cordifolia against SARS-CoV-2 protease, surface glycoprotein and RNA polymerase.
}

\section{Vasanthkumar Sagar}

Sparconn Life Sciences

Arun HS Kumar ( $\boldsymbol{D}$ arun.kumar@ucd.ie )

University College Dublin https://orcid.org/0000-0001-8422-0219

\section{Research Article}

Keywords: Protease inhibitors, RNA polymerase inhibitors, Coronavirus, Covid-19, Antiviral drugs, SARSCoV-2, Viral entry.

Posted Date: May 8th, 2020

DOl: https://doi.org/10.21203/rs.3.rs-27375/v1

License: (c) (i) This work is licensed under a Creative Commons Attribution 4.0 International License.

Read Full License 


\section{Abstract}

Background: Antiviral activity of natural compounds from Tinospora cordifolia (Amritaballi) were evaluated for their efficacy against SARS-CoV-2 targets involved in virus attachment and replication.

Materials and Methods: The binding efficacy (binding affinity, $\mathrm{K}_{\mathrm{i}}$ and $\mathrm{IC}_{50}$ values) of natural compounds from Tinospora cordifolia were tested using Insilco tools against four key SARS-CoV-2 targets i.e., 1) surface glycoprotein (6VSB) and 2) Receptor binding domain (6MOJ) both responsible for attachment of the virus to host cell, 3) RNA dependent RNA polymerase (6M71) and 4) main protease (6Y84) responsible for replication of the virus in the host cell.

Results: Berberine, Isocolumbin, Magnoflorine and Tinocordiside showed high binding efficacy against all the four key SARS-CoV-2 targets. Tinocordiside and Isocolumbin showed $\mathrm{IC}_{50}$ value of $<1 \mu \mathrm{M}$ against both 6 Y 84 and 6VSB.

Conclusion: At least four natural compounds from Tinospora cordifolia showed high binding efficacy against SARS-CoV-2 targets involved in attachment and replication of the virus. Hence validating the merit of using Tinospora cordifolia in the clinical management of infection caused by SARS-CoV-2.

\section{Introduction}

SARS-CoV-2 strain of coronavirus, which was first reported from the Wuhan region of China has caused a major disruption to everyday living worldwide. ${ }^{[1,2]}$ Recent reports suggest that the patients recovering from the illness caused by SARS-CoV-2 (COVID-19) ${ }^{[3]}$ don't develop effective immunity against SARS-CoV2. Considering this poor immunity against SARS-CoV-2 in the recovered patients, ${ }^{[3]}$ it is unlikely that a vaccine based approach or using hyperimmune serum will be beneficial in treating the patients with active infection. Also the currently available antiviral drugs (both approved and in clinical trials) are reported to have limited efficacy against SARS-CoV-2. ${ }^{[2,4,5]}$ Hence there is an urgent need for identifying effective antiviral drugs against SARS-CoV-2. ${ }^{[6]}$

Natural products have been viable and sustainable source of antimicrobial agents in the past and several natural compounds are reported to have antiviral properties. ${ }^{[5,7-9]}$ Recently we have shown the efficacy of neem and tulsi based natural compounds against the key SARS-CoV-2 targets. ${ }^{[10]}$ Tinospora cordifolia (TC), a deciduous, extensively-spreading, climbing herbaceous vine of the family Menispermaceae is considered an essential herbal plant in the Indian system of medicine. ${ }^{[11,12]}$ It is referred to by the following common names, Chakralakshanika (Sanskrit), Gurcha (Hindi) and Amritaballi (Kannada). The phytoconstituents of TC are reported to have antioxidant, antibacterial, antifungal, anti-diabetic, hypolipidemic, antimalarial, hepatoprotective and anticancer activities. ${ }^{[11-15]}$ Besides this, the plant extract is also shown to have wound healing, and immunomodulating properties. ${ }^{[15,16]}$ The leaf extract of $\mathrm{TC}$ is reported to have antimicrobial activity against gram-positive and gram-negative bacteria, clinically relevant fungal infections and malarial parasites. ${ }^{[13,15,16]}$ The antimicrobial properties of TC extracts is 
attributed to its phytoconstituents such as furanolactone, tinosporon, jateorine and columbin. ${ }^{[15-17]}$ The silver nanoparticles from Tinospora cordifolia were reported to be effective against chikungunya virus. ${ }^{[17]}$ Phytochemicals from TC are also reported be effective inhibitors of H1N1 viral proteins. ${ }^{[5]} \mathrm{TC}$ is also a vital component of Shilajatu Rasayana (an Ayurvedic preparation), which was reported to synergistically improve efficacy of anti-retroviral therapy in HIV positive patients. ${ }^{[18]}$ Considering the positive reports of antiviral activity of Tinospora cordifolia, in this study the efficacy of some selected natural compounds reported in Tinospora cordifolia extracts were screened using Insilco pharmacology against three SARSCoV-2 targets (Surface glycoproteins (6VSB, 6M0J); RNA dependent RNA polymerase (6M71) and Main Protease (6Y84)).

\section{Materials And Methods}

The 3D structure of SARS-CoV-2 targets (surface glycoproteins (6VSB; 6M0J), RNA dependent RNA polymerase (6M71) and main protease (6Y84)) were downloaded as PDB files from the protein data bank (https://www.rcsb.org/) and were optimized for molecular docking in the Chimera software. ${ }^{[19]}$

The structures of selected natural compounds in Tinospora cordifolia (Berberine, Tinocordiside, CordifolisideA, Jatrorrhizine, Magnoflorine, Isocolumbin, Sinapic acid, Syringin and Palmatine) were accessed from PubChem database and processed into PDB file format and minimised for molecular docking using the Chimera software. ${ }^{[19,20]}$ Molecular docking was performed to evaluate the binding efficacy of these compounds against the SARS-CoV-2 targets using AutoDock Vina (version 1.5.4) and the docked protein-ligand complex were visualised using the Chimera and PyMOL v 1.8.2.0 software $^{[19-}$ 22]. AutoDock-MGLTools was employed to visualize and modify the receptor and ligand structures to PDBQT file formats. The PDBQT file formats of the ligand and receptor were used for molecular docking using the AutoDock Vina program. Ligands were docked individually to the receptor with grid coordinates and grid boxes of specific sizes for each receptor centralised in the AutoDock-MGLTools. The output file was saved in the PDBQT format and the ligand-receptor binding affinity estimated as negative Gibbs free energy $(\Delta \mathrm{G})$ scores $(\mathrm{Kcal} / \mathrm{mol})$, were documented based on AutoDock Vina scoring function. Postdocking analyses were visualized using PyMOL and Chimera, giving details of the sizes, locations of binding sites, hydrogen-bond interactions of the docked ligand in various confirmations.

Simulation of dose response curves: Dose-response curves were modelled based on nonlinear regression analysis approach by specifying $\mathrm{IC}_{50}$ values as independent variable and response (\% inhibition) as dependent variable. $\mathrm{IC}_{50}$ values were estimated from the binding affinity values using the following formula IC $\mathrm{I}_{50}=\exp ($ deltaG/RT) $(1+([\mathrm{S}] / \mathrm{Km}))$. Where deltaG $=$ Binding affinity $(\mathrm{Kcal} / \mathrm{mol}), \mathrm{RT}=298 \mathrm{~K}, \mathrm{~S}=$ substrate concentration, $\mathrm{K}_{\mathrm{m}}=$ Michaelis constant. The increase in the ligand dose increases results in sequential changes to the response (\% receptor inhibition) eventually achieving minimum or maximum response limits. As the 20 to $80 \%$ response is linear, this was modelled using four-point logistic increments of $\mathrm{IC}_{50}$ values $(0.5 \mathrm{x}, 1 \mathrm{x}, 1.5 \mathrm{x}$ and $2 \mathrm{x})$ and averaged. The resulting equation from this was $\mathrm{y}=$ $26.362 x-158.85\left(R^{2}=0.9967\right)$. This one standard deviation increase and decrease of the $I_{50}$ values was 
estimated from this equation. The resulted three $\mathrm{IC}_{50}$ values estimated were used to calculate the IC 5 , $20,60,80$ and 100 values by employing a five-parameter logistic equation ${ }^{[23]}$. The means of the IC 5,20 , 60,80 and 100 values obtained (in $x$ axis) were plotted against the \% inhibition response (in y axis) to obtain the simulated dose response curves.

\section{Results}

Berberine and Isocolumbin showed superior binding affinity against all the four SARS-CoV-2 targets (6VSB, 6M0J, 6M71 and 6Y84) (Figure 1). Berberine, Isocolumbin, Magnoflorine and Tinocordiside had similar but best binding affinity against SARS-CoV-2 protease (6Y84) (Figure 1). Berberine and Isocolumbin had optimal binding affinity against SARS-CoV-2 surface glycoprotein (6VSB) as well as RNA polymerase (6M71) (Figure 1). Berberine, Tinocordiside and Isocolumbin had better binding affinity against SARS-CoV-2 receptor binding domain (6M0J) (Figure 1). All the natural compounds tested except Sinapic acid had binding efficacy ( $\mathrm{K}_{\mathrm{i}}$ and $\mathrm{IC}_{50}$ values) against the SARS-CoV-2 targets at a therapeutically feasible concentration (Figure 2). Tinocordiside and Isocolumbin showed $\mathrm{IC}_{50}$ value of $<1 \mu \mathrm{M}$ against both 6 Y84 and 6VSB (Figure 2) suggesting their high efficacy in preventing SARS-CoV-2 attachment to host cells and replication.

\section{Discussion}

The natural compounds from Tinospora cordifolia tested in this study showed therapeutically feasible efficacy against SARS-CoV-2 targets involved in attachment of the virus to host receptor (6VSB, 6MOJ) and its replication (6M71, 6Y84). Although antiviral properties of Tinospora cordifolia has been reported before against $\mathrm{H} 1 \mathrm{~N} 1$ and Chikungunya Virus, ${ }^{[5,17,18]}$ to best of our knowledge, this is the first study to report pharmacological activity of Tinospora cordifolia against coronavirus in general and SARS-CoV-2 in specific. Interestingly the reported efficacy (Binding affinity (Kcal/mol), Ki (mM) and IC50 (mM) values) of Favipiravir (-6.24 $\pm 0.35,26.17 \pm 1.81,52.32 \pm 3.62)$, Lopinavir/Ritonavir $(-6.97 \pm 0.45,7.72 \pm 0.22,15.44 \pm 0.43)$ against 6 Y84, efficacy of Remdesivir $(-7.69 \pm 0.29,2.28 \pm 0.16,4.55 \pm 0.33)$ against $6 \mathrm{M} 71$ and efficacy (Binding affinity $(\mathrm{Kcal} / \mathrm{mol}), \mathrm{Ki}(\mathrm{mM})$ and IC50 $(\mathrm{mM})$ values) of STGYC $(-6.10 \pm 0.27,33.39 \pm 1.57$, $66.79 \pm 3.14$ ) against $6 \mathrm{VSB}$ was either similar or inferior to the natural compounds from Tinospora cordifolia. ${ }^{[6,10]}$

6VSB and 6M0J are responsible for viral attachment, while 6Y84 (main Protease) and 6M71 (RNA dependent RNA polymerase) are involved in viral replication. ${ }^{[2,6,24]}$ Hence Tinospora cordifolia is likely to be efficacious in preventing SARS-CoV-2 attachment to the host cells and as well prevent replication of the virus. Several natural compounds from Tinospora cordifolia are reported to have anti-bacterial and immunostimulant properties, these pharmacological effects together with their specific antiviral effects against the SARS-CoV-2 may merit its use in the treatment of COVID-19. The validation of the pharmacological effects of Tinospora cordifolia against SARS-CoV-2 is timely as currently effective therapeutics to treat COVID-19 are not available. Tinospora cordifolia being a natural product with well- 
established safety profile through its time tested use in Ayurveda, ${ }^{[13,15]}$ can be quickly adapted for clinical use to manage COVID-19.

\section{Declarations}

Conflict of interest: none

\section{Acknowledgement}

Research support from University College Dublin-Seed funding/Output Based Research Support Scheme (AHSK), Royal Society-UK (AHSK) and Stemcology (AHSK) is acknowledged.

\section{References}

1. Fauci AS, Lane HC, Redfield RR. Covid-19 - Navigating the Uncharted. N Engl J Med. 2020. 382;(13). 1268-1269.

2. Stower H. Virological assessment of SARS-CoV-2. Nat Med. 2020. 26;(4). 465.

3. Prompetchara E, Ketloy C, Palaga T. Immune responses in COVID-19 and potential vaccines: Lessons learned from SARS and MERS epidemic. Asian Pac J Allergy Immunol. 2020. 38;(1). 1-9.

4. Dong L, Hu S, Gao J. Discovering drugs to treat coronavirus disease 2019 (COVID-19). Drug Discov Ther. 2020. 14;(1). 58-60.

5. Saikia S, Bordoloi M, Sarmah R, et al. Antiviral compound screening, peptide designing, and protein network construction of influenza a virus (strain a/Puerto Rico/8/1934 H1N1). Drug Dev Res. 2019. 80;(1). 106-124.

6. Kumar AHS, Sharma V. Acetamido-Propanoic Acid Derived Compounds as Protease Inhibitors to Target Coronaviruses. BEMS Reports. 2019. 5;(2). 20-22.

7. Goothy SSK, Goothy S, Choudhary A, et al. Ayurveda's Holistic Lifestyle Approach for the Management of Coronavirus disease (COVID-19): Possible Role of Tulsi. Int. J. Res. Pharm. Sci. 2020. 11. 16-18.

8. Sohail MN, Rasul F, Karim A, et al. Plant as a Source of Natural Antiviral Agents. Asian Journal of Animal and Veterinary Advances. 2011. 6. 1125-1152.

9. Tiwari V, Darmani NA, Yue BY, et al. In vitro antiviral activity of neem (Azardirachta indica L.) bark extract against herpes simplex virus type-1 infection. Phytother Res. 2010. 24;(8). 1132-40.

10. Kumar AHS. Molecular docking of natural compounds from tulsi (Ocimum sanctum) and neem (Azadirachta indica) against SARS-CoV-2 protein targets. BEMS Reports. 2020. Accepted.

11. Baden LR, Rubin EJ. Covid-19 - The Search for Effective Therapy. N Engl J Med. 2020.

12. Kalikar MV, Thawani VR, Varadpande UK, et al. Immunomodulatory effect of Tinospora cordifolia extract in human immuno-deficiency virus positive patients. Indian J Pharmacol. 2008. 40;(3). 10710. 
13. Agarwal S, Ramamurthy PH, Fernandes B, et al. Assessment of antimicrobial activity of different concentrations of Tinospora cordifolia against Streptococcus mutans: An in vitro study. Dent Res J (Isfahan). 2019. 16;(1). 24-28.

14. Sachan S, Dhama K, Latheef SK, et al. Immunomodulatory Potential of Tinospora cordifolia and CpG ODN (TLR21 Agonist) against the Very Virulent, Infectious Bursal Disease Virus in SPF Chicks. Vaccines (Basel). 2019. 7;(3).

15. Singh D, Chaudhuri PK. Chemistry and Pharmacology of Tinospora cordifolia. Nat Prod Commun. 2017. 12;(2). 299-308.

16. Sharma P, Dwivedee BP, Bisht D, et al. The chemical constituents and diverse pharmacological importance of Tinospora cordifolia. Heliyon. 2019. 5;(9). e02437.

17. Sharma V, Kaushik S, Pandit P, et al. Green synthesis of silver nanoparticles from medicinal plants and evaluation of their antiviral potential against chikungunya virus. Appl Microbiol Biotechnol. 2019. 103;(2). 881-891.

18. Gupta GD, Sujatha N, Dhanik A, et al. Clinical Evaluation of Shilajatu Rasayana in patients with HIV Infection. Ayu. 2010. 31;(1). 28-32.

19. Yang Z, Lasker K, Schneidman-Duhovny D, et al. UCSF Chimera, MODELLER, and IMP: an integrated modeling system. J Struct Biol. 2012. 179;(3). 269-78.

20. Trott O, Olson AJ. AutoDock Vina: improving the speed and accuracy of docking with a new scoring function, efficient optimization, and multithreading. J Comput Chem. 2010. 31;(2). 455-61.

21. O'donoghue SI, Goodsell DS, Frangakis AS, et al. Visualization of macromolecular structures. Nat Methods. 2010. 7;(3 Suppl). S42-55.

22. Seeliger D, De Groot BL. Ligand docking and binding site analysis with PyMOL and Autodock/Vina. J Comput Aided Mol Des. 2010. 24;(5). 417-22.

23. Ricketts $\mathrm{JH}$, Head GA. A five-parameter logistic equation for investigating asymmetry of curvature in baroreflex studies. Am J Physiol. 1999. 277;(2). R441-54.

24. Choy KT, Wong AY, Kaewpreedee P, et al. Remdesivir, lopinavir, emetine, and homoharringtonine inhibit SARS-CoV-2 replication in vitro. Antiviral Res. 2020. 178. 104786.

\section{Figures}



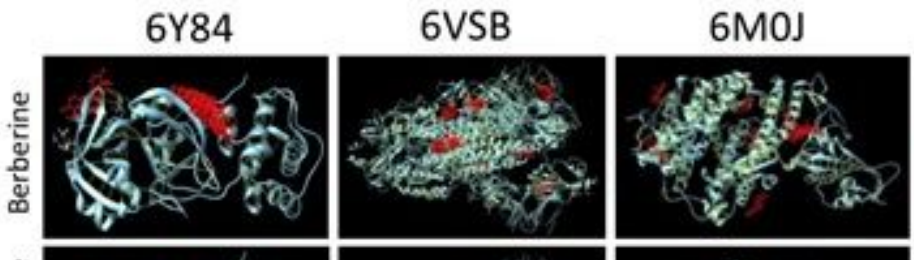

$6 \mathrm{M} 71$
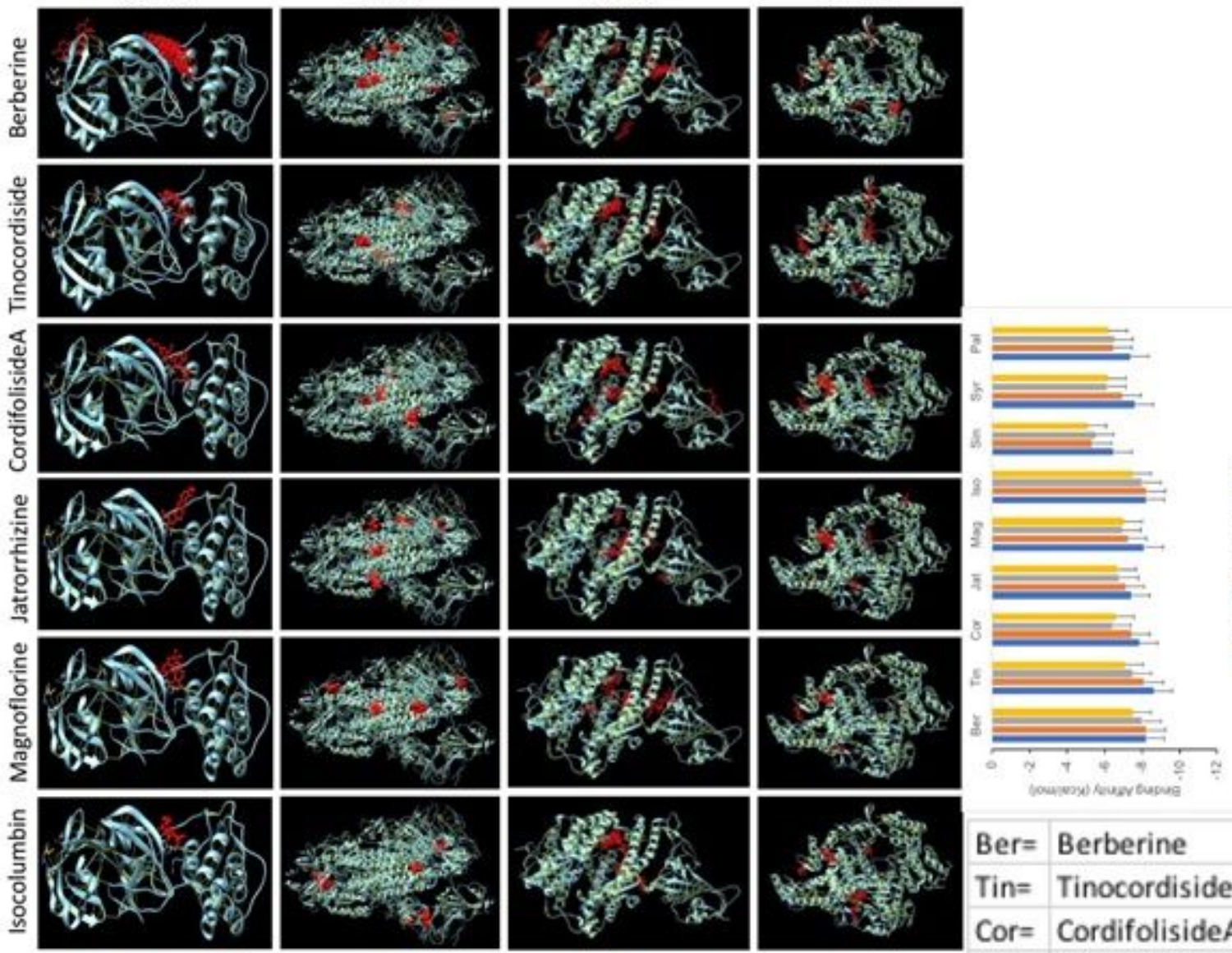

Ber $=$ Berberine

Tin $=$ Tinocordiside

Cor $=$ Cordifoliside $A$
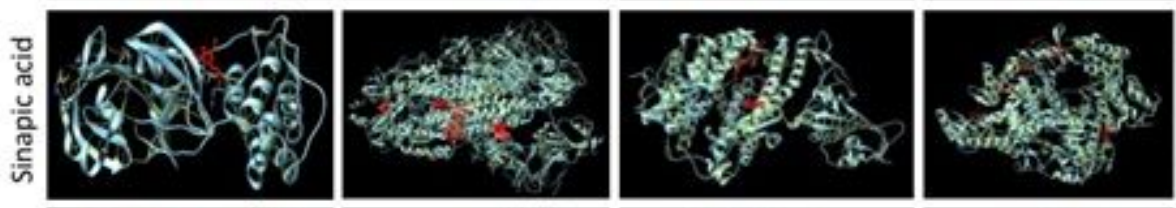

Jat $=$ Jatrorrhizine

Mag= Magnoflorine

Iso $=$ Isocolumbin

Sin $=$ Sinapic acid
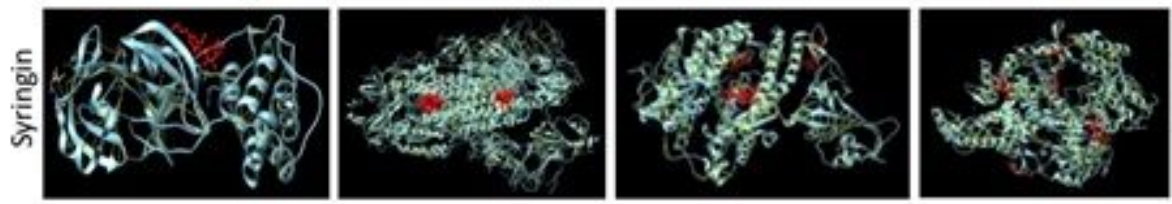

Syr $=$ Syringin

Pal $=$ Palmatine
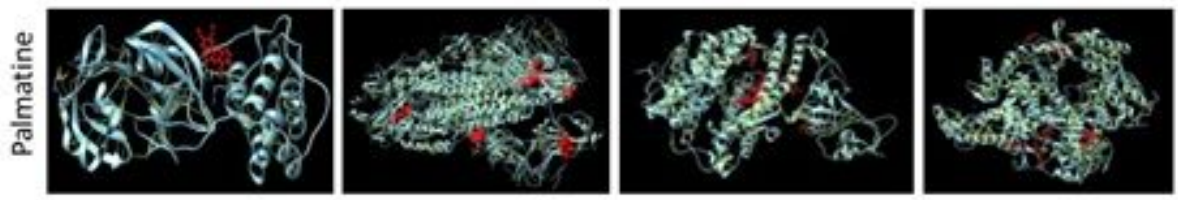

Figure 1

Binding location and affinity (Kcal/mol) of various confirmation of natural compounds (red) from Tinospora cordifolia against SARS-CoV-2 targets (surface glycoproteins (6VSB), receptor binding domain $(6 \mathrm{MOJ}), \mathrm{RNA}$ dependent RNA polymerase (6M71) and main protease (6Y84)). The table represents the mean $\square S D$ of binding affinity $(\mathrm{Kcal} / \mathrm{mol})$ of nine different confirmation of natural compounds against the specific SARS-CoV-2 target. 


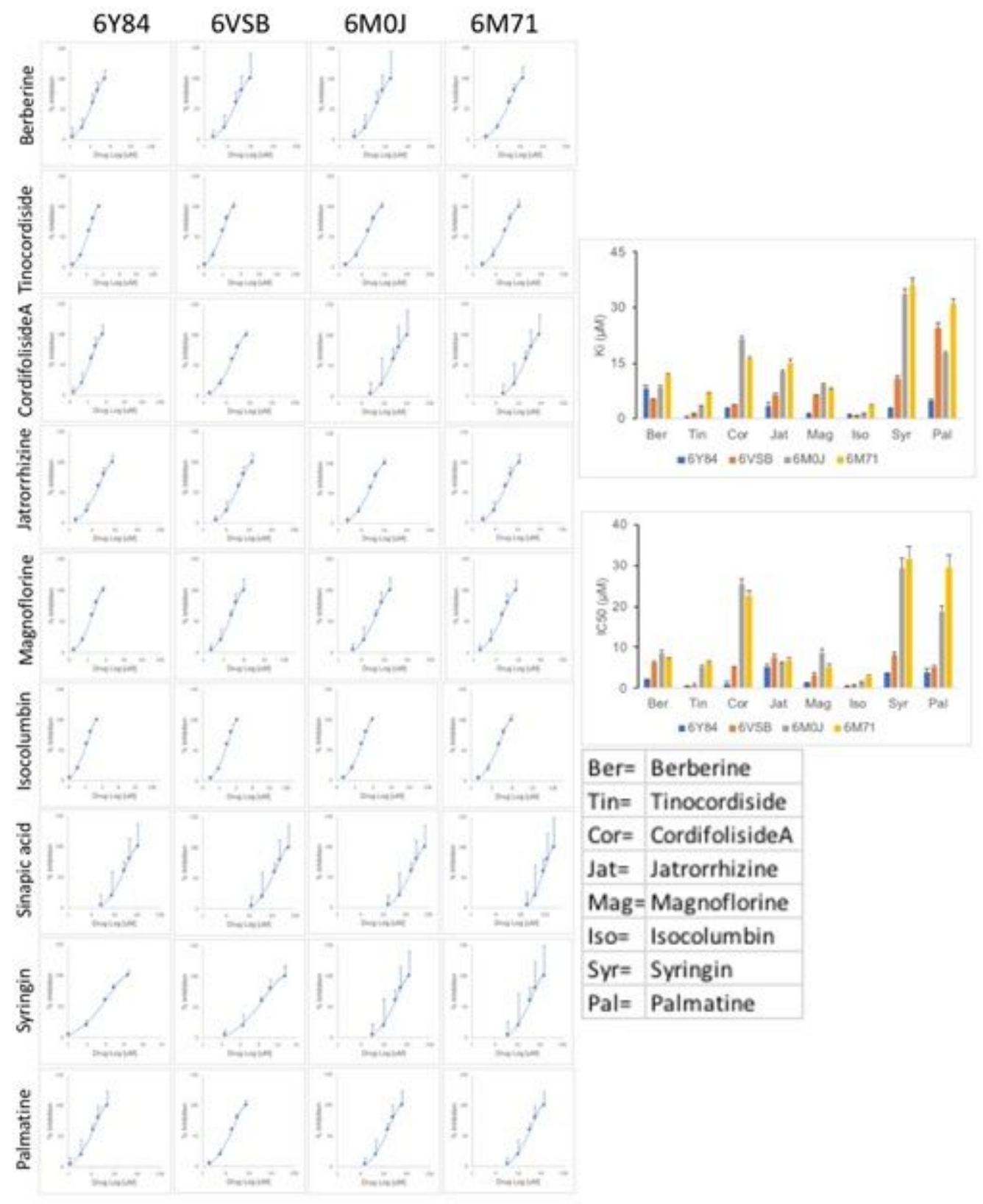

Figure 2

Dose response curves and binding efficacy (Ki and IC50; $\square \mathrm{M}$ ) of natural compounds from Tinospora cordifolia against SARS-CoV-2 targets (surface glycoproteins (6VSB), receptor binding domain (6MOJ), RNA dependent RNA polymerase (6M71) and main protease (6Y84)). The table represents the mean $\square$ SD of binding efficacy (Ki and IC50; $\square \mathrm{M}$ ) of natural compounds against the specific SARS-CoV-2 target. 